\title{
Bewehrung von Estrichen
}

Früher wurden schwimmende Estriche häufig armiert. Dies mit der irrigen Absicht dadurch die Festigkeit und Tragfähigkeit des Estrichs zu erhöhen. Beides hat sich jedoch als falsch erwiesen. Geblieben ist die Eigenschaft bei vorkommen von Rissen Höhenversätze zu vermeiden. Risse verhindern, aus welchem Grund sie auch immer entstehen, können Armierungen nicht.

Meist wird durch die problematische Einarbeitung der Bewehrung das Ergebnis verschlechtert. Da bereits der Riss im Estrich, welcher sich z. B. in einem keramischen Bodenbelag fortsetzt einen wesentlichen Mangel begründet, würde die Verhinderung von Höhenversätzen daran nichts ändern.

Da aus der Sicht der Autoren der technische Unsinn einer Bewehrung zwischenzeitlich in Fachkreisen gängige Meinung ist wird auf eine Vertiefung dieser Thematik an dieser Stelle verzichtet. 